\title{
Septic Acute Kidney Injury: The Culprit Is Inflammatory Apoptosis rather than Ischemic Necrosis
}

\author{
R. Jacobs ${ }^{\text {a }}$ P.M. Honore ${ }^{\mathrm{a}}$ O. Joannes-Boyau ${ }^{\mathrm{d}}$ W. Boer ${ }^{\mathrm{c}} \quad$ J. De Regt ${ }^{\mathrm{a}}$ \\ E. De Waele ${ }^{a}$ V. Collin ${ }^{b}$ H.D. Spapen ${ }^{a}$

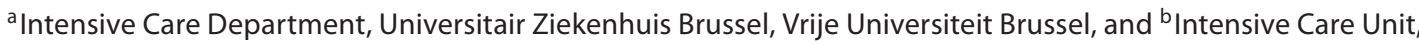 \\ Cliniques de l'Europe-Site St Michel, Brussels, and 'Department of Anaesthesiology and Critical Care Medicine, \\ Ziekenhuis Oost-Limburg, Genk, Belgium; ${ }^{\mathrm{d}}$ Departement d'Anesthesie Reanimation II (DAR II), Haut Leveque \\ University Hospital of Bordeaux, University of Bordeaux 2, Pessac, France
}

\section{Key Words}

Hemofiltration - Sepsis - Acute tubular apoptosis - Acute kidney injury $\cdot$ High volume hemofiltration - Mediator removal $\cdot$ Septic acute kidney injury

\begin{abstract}
For a long time, acute kidney injury (AKI) was considered to be a primarily hemodynamic condition characterized by a reduction of renal blood flow, induced by either cardiogenic or distributive (septic) shock. Consequently, all efforts to treat AKI were essentially concentrated on increasing renal flow by enhancing cardiac flow output and perfusion pressure. At the beginning of this decade, Bellomo and co-workers produced new and intriguing data in an animal model of septic AKI that undermined existing concepts. They observed that medullar and cortical renal blood flow were both maintained and even increased in septic shock, underscoring that septic AKI was a totally different physiological phenomenon than nonseptic AKI. Also, apoptosis was found to play a more important role in sepsis and septic shock than pure necrosis. Despite these findings, the role of apoptosis as a main mechanism of organ dysfunction remains topic of debate.

Copyright $\odot 2011$ S. Karger AG, Basel
\end{abstract}

\section{Hemodynamics as the Major Player}

Acute kidney injury (AKI) occurring in the intensive care unit (ICU) was until recently considered to be a hemodynamic 'low flow' complication during a state of shock. Consequently, all efforts to prevent or treat AKI primarily aimed to increase renal blood flow by enhancing cardiac output and perfusion pressure [1]. At the beginning of this decade, however, Bellomo's group published new data in experimental septic AKI that contradicted these concepts. They demonstrated that both medullar and cortical renal blood flow were maintained and even increased during septic shock [2] which proves that septic AKI had a different physiopathological behavior than non-septic AKI.

\section{Is Inflammation Playing a New Role?}

Ample proof exists to sustain a more prominent role of apoptosis rather than pure necrosis in the pathophysiology of sepsis and septic shock [3]. Despite substantial advances being made to elucidate the etiology of lesions such as tubular apoptosis [4], debate is still ongoing about

\section{KARGER}

Fax +41613061234 E-Mail karger@karger.ch www.karger.com
Patrick M. Honoré, MD

Head of Clinics, Intensive Care Department

Universitair Ziekenhuis Brussel, Vrije Universiteit Brussel (VUB)

BE-1090 Brussels, Jette (Belgium)

Tel. +32 2474 9097, E-Mail Patrick.Honore@uzbrussel.be 
the possible key role of apoptosis in mechanisms of organ dysfunction in humans [5]. In a recently published study, apoptosis was put forward as a major player in septic AKI [6]. In their introduction, the authors acknowledged a paucity of histopathologic data in human studies, most of them published before 1980 [6]. Kidney biopsies from 19 consecutive patients who died from septic shock were compared with postmortem biopsies taken from 8 trauma patients and from 9 patients with nonseptic AKI [6]. Acute tubular apoptosis was demonstrated in septic AKI whereas almost no apoptosis was detected in the non-septic AKI patients. In this study, three different techniques to confirm apoptosis were applied: routine microscopy, the TUNEL (terminal-deoxynucleotidyl-transferase-mediated dUTP-digoxigenin nick and labeling) method and activated caspase 3 labeling. The two last techniques enabled to detect $6 \%$ apoptosis in the septic group versus only $1 \%$ in the nonseptic group $(\mathrm{p}<0.0001)$. However, some control biopsies were retrieved from patients who died at the scene of trauma, which may have limited the development of any type of histologic lesions in the kidney. On the other hand, a subset of six other controls consisted of out-of-hospital cardiac arrest patients who most likely suffered cardiogenic shock before dying. Therefore, the latter group may more reliably represent non-septic AKI with its accompanying hemodynamically related lesions. Further drawbacks of the study are the cadaveric nature of the biopsies, which precludes interpretation of potentially reversible changes that occur in recovering patients and some control groups being historical controls. From a theoretical point of view, necrosis results from the additive effect of a number of independent biochemical events that are activated by severe depletion of cell energy stores. In contrast, the process of apoptosis follows a coordinated, predictable and predetermined pathway. These biochemical differences between apoptosis and necrosis have important therapeutic implications. Once a cell has been severely injured, necrosis is difficult to prevent whilst the apoptotic pathway can be modulated to maintain cell viability [7]. Theoretically, the components of the apoptotic pathway that could be amenable to therapeutic modulation are numerous [8].

\section{Caspase Cascades as a New Possible Avenue}

Within this new perspective of septic AKI or apoptotic-inflammatory AKI, the administration of caspase inhibitors (CI) gains increasing importance. Indeed, CI ameliorate ischemia-reperfusion injury in different organs, including the kidney. However, it remains uncertain to what extent this protective effect of caspase inhibition is caused by reduced (intrarenal) inflammation or by amelioration of renal tubular cell loss due to apoptosis [9]. In addition to caspase inhibition, the apoptotic pathway offers many opportunities for therapeutic interventions that may prevent or reduce renal tubular cell apoptosis and, as such, renal function impairment. In a rat model of glycerol-induced AKI (Gly-AKI) [10], caspases were found to participate in inflammation, apoptosis, vasoconstriction, and finally tubular necrosis. Early caspase inhibition attenuated these processes and significantly improved renal function [10]. Apoptosis also occurs in the kidney during LPS-induced AKI (LPS-I-AKI) [10] but its relative importance in this condition remains unproven. Guo et al. [11] hypothesized that treatment with a caspase inhibitor would protect mice from LPS-I-AKI. Mice, injected with LPS, were either treated with a broad-spectrum caspase inhibitor or received placebo. Caspase inhibition was found to protect against LPS-I-AKI, not only by preventing apoptotic cell death but also by inhibiting inflammation [11] The authors concluded that apoptotic kidney cells may act as a source of local inflammation producing subsequent non-apoptotic renal injury [11]. Another recent study [12] showed that plasma from septic burn patients with AKI could initiate pro-apoptotic effects and in vitro functional alterations of renal tubular cells and podocytes that correlated with the degree of proteinuria and renal dysfunction. In this model, additive and even synergistic effects of sepsis and burn injury were noticed.

\section{Role of Extracorporeal Therapies in Preventing This Cascade of Events}

Further research for therapeutic interventions is warranted in several areas such as binding and elimination of endotoxin by extracting the source of sepsis, blocking of various apoptotic pathways, or even extracorporeal removal of circulating toxic mediators using high volume hemofiltration, high permeability hemofiltration and plasma filtration coupled with absorption [13]. A recent study showed that extracorporeal therapy with polymyxin B therapy (PMX) reduced the pro-apoptotic activity of plasma of septic patients on cultured renal cells, providing further evidence for a preponderant role of apoptosis in the development of sepsis-related AKI [14]. It seems 
likely that plasma separation techniques can prove beneficial in renal injury through the removal of pro-apoptotic factors and cytokines.

\section{Importance of Renal Replacement Therapy Type, Dosing and Timing on the Cascade of Events in Septic Acute Kidney Injury}

Type, dose and timing of initial renal replacement therapy (RRT) [13] seem to have important consequences. Bell and co-workers recently demonstrated the importance of the initially chosen renal replacement therapy on AKI recovery rates in ICU patients [15]. In line with this finding, the recently published VA/NIH (ATN, acute tubular necrosis) trial [16] showed that a delay in starting treatment most probably was responsible for the high rate of dialysis dependency as shown by a recent review [17]. Finally, because of some important shortcomings of the ATN trial [18], an expert panel from the SRLF in France [17] (not necessarily the strongest advocates of the $35-\mathrm{ml} / \mathrm{kg} / \mathrm{h}$ dose) felt obliged to recommend the continued use of the $35 \mathrm{ml} / \mathrm{kg} / \mathrm{h}$ dose in to treat septic AKI in ICU patients thereby softening somewhat the message of the 'RENAL' (Randomised Evaluation of Normal vs. Augmented Level of Replacement Therapy) study which was not designed for the evaluation of septic AKI [19]. On the other hand, Palevsky et al. [20] recently turned down the idea that their study supported an approach of therapeutic nihilism, as suggested by Ronco et al. [18]. They argued that a less intensive strategy might provide a level of renal support that often exceeds routine clinical practice and suggested to put greater emphasis on ensuring the actual delivery of an appropriate prescribed dose of therapy. On top of this, they challenged the hypothesis that the use of a fixed dose of therapy during an ongoing dynamic episode of AKI is not always appropriate. They agreed that treatment should be individualized and that more intensive therapy may be required in some situations [20]. It is of paramount importance to realize that septic AKI has a higher mortality rate than non-septic AKI [21]. In fact, the higher mortality of sepsis-associated AKI is not linked to intrinsic renal lesions alone but correlates well with remote sepsis-induced tissue inflammatory damages [21]. It is also known that AKI and in particular septic AKI can induce a state of immunoparalysis, thereby increasing the risk of subsequent infection [22]. It is noteworthy that Lerolle et al. [6] totally contradict a recent systematic review on that topic by the Bellomo group [23]. The review had concluded that no consistent renal histopathological changes were found in human or experimental septic AKI. In fact, most studies reported normal histology or only mild non specific changes, while ATN was relatively uncommon [23]. Lerolle et al. [6], however, evocated a well-defined septic pattern characterized by an increased level of tubular apoptosis and renal inflammation.

\section{Challenging the Concept of the Prerenal Azotemia Paradigm in Septic Acute Kidney Injury}

When considering septic AKI as a disease entity in which hemodynamic compromise of the kidney alone is no longer the rule, a revision of the 'pre-renal' AKI concept can be envisaged. Several assumptions associated with the 'pre-renal azotemia paradigm' will be in violation of this revised definition. It is not evidenced that ATN is the histopathological substrate of septic AKI and, above all, it is not proven that urine tests can discriminate between functional and structural AKI.

\section{Potential Risks of Considering Additional Fluid Volume Loading in Septic Acute Kidney Injury}

In developed countries, septic AKI actually accounts for almost $50 \%$ of cases of severe AKI in ICU patients. In this context, the concept of additional fluid loading in septic AKI seems erroneous. Indeed, if an adequately volume-resuscitated patient remains hypotensive, further fluid challenge will likely fail to augment an already increased renal output but may severely harm the patient. Thus, volume loading should be abandoned earlier in septic AKI [24, 25].

\section{Further Research Options}

The peptide ghrelin exerts renal protective effects by inhibiting pro-inflammatory cytokines, particularly TNF- $\alpha$, in the circulation and the kidney. Ghrelin may thus hold promise for managing endotoxemia-induced AKI [26]. Although further evidence confirming this beneficial effect is definitely needed [16], studies with this agent in septic AKI seem justified. Modulating the caspase cascade or even entire inflammatory pathways at the renal level as well as looking for new modes of intervention are the way forward. Finally, in a fluid-resuscitated 
animal model of septic shock, low-dose arginine vasopressin caused less tubular apoptosis, systemic inflammation and kidney damage than noradrenaline [27], suggesting that the type of vasopressor used for resuscitation may also influence septic AKI. In a relatively recent paper, Janssen van Doorn et al. [28] could not demonstrate any effect on urine output, tubular function, or mortality in a small cohort of patients with severe sepsis who received adjuvant DrotAA treatment. Recently, Kellum's group has identified that the renin-angiotensin-aldosterone system, especially angiotensin II, contributes to kidney injury through the angiotensin II type 1 receptor and this might also represent a new potential avenue of treatment [29].

\section{Conclusions}

In conclusion, exciting developments on many fronts are forthcoming. In the light of recent findings, revision of outdated concepts and accordingly changes in therapeutic approach seem inevitable. The modulation of inflammatory pathways, both directly and by optimalization of plasma separation techniques, is promising [30]. Correct application of fluid regimes and vasopressors for resuscitation of septic AKI merit further investigation. Early detection of renal dysfunction using new biomarkers can help to direct goals of intervention. Clinical practice may soon be changing.

\section{References}

-1 Schrier RW, Wang W: Acute renal failure and sepsis. N Engl J Med 2004;351:159-169.

$\checkmark 2$ Wan L, Bagshaw SM, Langenberg C, Saotome T, May C, Bellomo R: Pathophysiology of septic acute kidney injury: what do we really know? Crit Care Med 2008;36:198-203.

3 Hotchkiss RS, Swanson PE, Freeman BD et al: Apoptotic cell death in patients with sepsis, shock, and multiple organ dysfunction. Crit Care Med 1999;27:1230-1251.

-4 Bellomo R, Wan L, Langenberg C, May C: Septic acute kidney injury: new concepts. Nephron Exp Nephrol 2008;4:95-100.

5 Abraham E, Singer M: Mechanisms of sepsis-induced organ dysfunction. Crit Care Med. 2007;35:2408-2416.

6 Lerolle N, Nochy D, Guérot E, et al: Histopathology of septic shock induced renal injury: apotosis and leukocytic infiltration. Intensive Care Med 2010;36:471-478.

7 Devarajan P: Cellular and molecular derangements in acute tubular necrosis. Curr Opin Pediatr 2005; 17:193-199.

-8 Rana A, Sathyanarayana P, Lieberthal W: Role of apoptosis of renal tubular cells in acute renal failure: therapeutic implications. Apoptosis 2001;6:83-102.

-9 Boneggio R, Lieberthal W: Role of apoptosis in the pathogenesis of acute renal failure. Curr Opin Nephrol Hypertens 2002;11:301308.

10 Homsi E, Janino P, de Faria JB: Role of caspases on cell death, inflammation, and cell cycle in glycerol-induced acute renal failure. Kidney Int 2006;69:1385-1392.

-11 Guo R, Wang Y, Minto AW, Quigg RJ, Cunningham PN: Acute renal failure in endotoxemia is dependant on caspase activation. J Am Soc Nephrol 2004;15:3093-3102.

12 Mariano F, Cantaluppi V, Stella M, et al: Circulating plasma factors induce tubular and glomerular alterations in septic burns patients. Crit Care 2008;12:R42.
13 Honore PM, Joannes-Boyau O, Boer W, Collin V: High-volume hemofiltration in sepsis and SIRS: current concepts and future prospects. Blood Purif 2009;28:1-11.

14 Cantaluppi V, Assenzio B, Pasero D, et al: Polymyxin-B hemoperfusion inactivates circulating proapoptotic factors. Intensive Care Med 2008;34:1638-1645.

15 Bell M, SWING, Granath F, Schon S, Ekbom A, Martling CR: Continuous renal replacement therapy is associated with less chronic renal failure than intermittent haemodialysis after acute renal failure. Intensive Care Med 2007;33:773-780.

16 Palevsky PM, Zhang JH, O’Connor TZ, et al: Intensity of renal support in critically ill patients with acute kidney injury. $\mathrm{N}$ Engl J Med 2008;359:7-20.

17 Ridel C, Balde MC, Rondeau E, Vinsonneau $\mathrm{C}$ : Dose of dialysis in intensive care unit. Reanimation 2009; 18:385-396.

18 Ronco C, Cruz D, Oudemans-van-Straaten HM, Honoré PM, House A, Bin D, Gibney N: Dialysis dose in acute kidney injury: no time for therapeutic nihilism - a critical appraisal of the Acute Renal Failure Trial Network study. Crit Care 2008;12:308.

19 Bellomo R, Cass A, Cole L, et al: Intensity of continuous renal-replacement therapy in critically ill patients. N Engl J Med 2009;361: 1627-1628

20 Palevsky PM, O'Connor TZ, Chertow GM, Crowley ST, Zhang JH, Kellum JA: Intensity of renal replacement therapy in acute kidney injury: perspective from within the Acute Renal Failure Trial Network Study. Crit Care 2009; $13: 310$

-21 Parmar A, Langenberg C, Wan L, May CN, Bellomo R, Bagshaw SM: Epidemiology of septic acute kidney injury. Curr Drug Targets 2009;10:1169-1178.
22 Honore PM, Jacobs R, Boer W, Joannes-Boyau O: Sepsis and AKI: more complex than just a simple question of chicken and egg. Intensive Care Med 2011;37:186-189.

23 Langenberg C, Bagshaw SM, May CN, Bellomo R: The histopathology of septic acute kidney injury: a systematic review. Crit Care 2008; 12:R38.

24 Bellomo R, Bagshaw S, Langenberg C, Ronco C: Pre-renal azotemia: a flawed paradigm in critically ill septic patients? Contrib Nephrol. Basel, Karger, 2007, vol 156, pp 1-9.

25 Honore PM, Jacobs R, Joannes-Boyau O, Boer W, De Waele E, De Regt J, Collin V, Spapen HS: Septic AKl in ICU patients. Diagnosis, pathophysiology and treatment type, dosing and timing: a comprehensive review of recent and future developments. Annals of Intensive Care 2011;1: in press.

26 Wang W, Bansal S, Falk S, Ljubanovic D, Schrier RW: Ghrelin protects mice against endotoxemia-induced acute kidney injury. Am J Physiol Renal Physiol 2009;297:F1032-F1037.

27 Simon F, Giucidi R, Scheurle A, et al: Comparison of cardiac, hepatic, and renal effects of arginine vasopressin and noradrenaline during porcine fecal peritonitis: a randomized controlled trial. Crit Care 2009;13:R113.

28 Janssen van Doorn K, Spapen HS, Geers C, Diltoer M, Shabana W: Sepsis-related acute kidney injury: a protective effect of drotrecogin alpha (activated) treatment? Acta Anaesthesiol Scand 2008,52:1259-1264.

-29 Wen X, Murugan R, Peng Z, Kellum JA: Pathophysiology of acute kidney injury: a new perspective. Contrib Nephrol. Basel, Karger, 2010, vol 165, pp 39-45.

30 Honore PM, Joannes-Boyau O, Boer W, Collin V, Jennes S: Continuous haemofiltration in 2009: what's new for clinicians regarding: pathophysiology, technique to be privileged and dose to be recommended - in-depth review. Blood Purif 2009;28-135-143. 